\title{
A MORPHOMETRIC STUDY OF THE PAPILLARY MUSCLES OF THE RIGHT VENTRICLE OF HUMAN CADAVERIC HEARTS IN NORTH-WEST INDIAN POPULATION
}

\author{
Kirandeep Kaur Aulakh¹, Amit Kumar Saxena2, Prachi Saffar Aneja³, Savita Bansal ${ }^{4}$ \\ ${ }^{1}$ Assistant Professor, Department of Anatomy, FMHS, SGT University, Gurgaon. \\ ${ }^{2}$ Associate Professor, Department of Anatomy, FMHS, SGT University, Gurgaon. \\ ${ }^{3}$ Associate Professor, Department of Anatomy, FMHS, SGT University, Gurgaon. \\ ${ }^{4}$ Associate Professor, Department of Pathology, Manav Rachna Dental College, Faridabad.
}

\section{ABSTRACT}

\section{BACKGROUND}

Atrioventricular (AV) valvular apparatus comprises of AV orifice and its annulus, valvular leaflets, chordae tendineae and papillary muscles. The study was done with a purpose to find out the gross morphology of papillary muscles of right ventricle and to compare any gender differences. This is helpful in understanding right atrioventricular valve dysfunction like regurgitations and also helpful in valve repair surgeries.

The aim of this study was

1. To note the shape, origin, number of heads and other gross features of papillary muscles of right ventricle.

2. To find out sexual difference in the gross morphology of papillary muscles of right ventricle.

\section{MATERIALS AND METHODS}

The study was carried out in 30 apparently normal cadaveric hearts after fixing in $10 \%$ formalin. The right ventricle was opened after giving an incision and gross morphology of papillary muscles of right ventricles was studied by using Vernier calliper.

Statistical Analysis- In statistical analysis SPSS software was used and unpaired 't' test was used. P value less than 0.05 was taken as significant.

\section{RESULTS AND CONCLUSIONS}

It was found that anterior and posterior papillary muscles of right ventricle were always present while septal group of papillary muscles were absent in $10 \%$ cases. Number of heads of papillary muscles ranged from 1 to 4 in right ventricle. Length of anter ior papillary muscle was more in males while rest of the papillary muscles of right ventricles were longer in females. The origin of the Anterior Papillary Muscle (APM) was mainly from lower $1 / 3$ of the ventricular wall (80.5\%). In rest of the cases (19.5\%) the muscle took origin from middle 1/3 of the right ventricular wall. Muscle belly of APM was intraluminal in all the cases. No mixed or sessile types were found.

\section{KEYWORDS}

Atrioventricular Valve, Papillary Muscles, Right Ventricle.

HOW TO CITE THIS ARTICLE: Aulakh KK, Saxena AK, Aneja PS, et al.A morphometric study of the papillary muscles of the right ventricle of human cadaveric hearts in north-west Indian population. J. Evolution Med. Dent. Sci. 2016;5(88):6553-6559, DOI: 10.14260/Jemds/2016/1482

\section{BACKGROUND}

Atrioventricular (AV) valvular apparatus comprises of $\mathrm{AV}$ orifice and its annulus, valvular leaflets, chordae tendineae and papillary muscles. ${ }^{1}$ Tricuspid valve complex comprises of tricuspid AV orifice and its associated annulus, valvular leaflets or cusps, chordae tendineae of various types and papillary muscles. ${ }^{2}$ Tricuspid valve orifice is the largest valve orifice with an average circumference of $11.4 \pm 1.1 \mathrm{~cm}$ in males and $10.8 \pm 1.3 \mathrm{~cm}$ in females. ${ }^{3}$ Valvular orifice is surrounded by a uniform ring of collagenous tissue (annulus). Papillary muscles in right ventricle comprise of anterior, posterior and septal muscles. ${ }^{2}$ Anterior papillary muscle (APM) is the largest and occasionally bifid. Its base arises from the right anterolateral ventricular wall below the anteroposterior

Financial or Other, Competing Interest: None.

Submission 28-09-2016, Peer Review 21-10-2016,

Acceptance 28-10-2016, Published 02-11-2016.

Corresponding Author:

Dr. Amit Kumar Saxena

Flat No. 4080 FF I.P. Extn. Sector 49,

Faridabad-121001, Haryana, India.

E-mail:sonuamit33@gmail.com

DOI: $10.14260 /$ jemds $/ 2016 / 1482$ commissure and blends with the right end of the septomarginal trabecula. Posterior papillary muscle (Ppm) arises from the ventriculoseptal myocardium below the posteroseptal commissure. It is frequently bifid or trifid. The papillary muscles supporting septal leaflet have been classified into 2 groups. 4 These are medial papillary complex (MPC) and septal papillary muscles (SPM).

Normal valve function depends upon the anatomic and mechanical integrity of the atrioventricular ring, the valve leaflets, the chordae tendineae and the papillary muscles, as well as upon proper integration of the time relations between contraction of the papillary muscle and contraction of the free ventricular wall. ${ }^{1}$ Papillary muscle contraction normally continues synchronously with ventricular contraction and thereby supports the chordae tendineae and prevents overshoot of the leaflets during ventricular systole. 5 In papillary muscle dysfunction, contraction is absent or ineffective. Rupture of one or more chordae tendineae results in acute loss of leaflet support leading to abrupt onset of mitral regurgitation. Regurgitation also occurs in rupture of papillary muscle. 6,7 
The gross features of papillary muscles are very important for cardiac surgeons for the valvular surgeries like valve repair and replacement.

\section{Aims}

1. To note the shape, origin, number of heads and other gross features of papillary muscles of right ventricle.

2. To find out sexual difference in the gross morphology of papillary muscles of right ventricle.

\section{MATERIALS AND METHODS}

The present study was carried out in 30 apparently normal cadaveric hearts, which were available in the museum of the Department of Anatomy, Govt. Medical College and Hospital and Postgraduate Institute of Medical Education and Research, Chandigarh. The ages of the cases ranged from 17 to 75 years. There were 17 male and 13 female hearts. The hearts, which were fixed in $10 \%$ formalin, were washed under running tap water.

Right ventricle was opened along its acute margin by an incision from the right atrium to the apex of the right ventricle. The section passed near anteroposterior commissure of right $A V$ valve to avoid sectioning the papillary muscles. The hearts were opened and washed under running tap water to remove blood clots. Gross morphology of the papillary muscles of the right ventricles was studied and noted.

Morphology of the papillary muscles of the right ventricle was noted which included number of heads, length, shape, origin and other gross features. The papillary muscles were studied and measured in situ with the help of a Vernier calliper. A head of a papillary muscle is defined as a muscle that is directly attached to the ventricular wall and its length was measured from this origin to the highest point of the muscle. The maximum length was taken. All measurements were made twice and the mean values were recorded. The site of the origin of the papillary muscles from the ventricular wall was also observed.

The values obtained from various measurements were tabulated and averages were calculated. Statistical analysis was done using unpaired ' $t$ ' test to compare lengths of papillary muscles. The present observations were compared with the other studies available in the literature to note any differences.

\section{RESULTS}

The incidence, length, number of heads, origin, protrusion of muscle bellies were observed in the papillary muscles of right ventricle.

\section{Right Ventricle}

There are three groups of papillary muscles in the right ventricle. These are anterior, posterior and papillary muscles of septal group.

\section{Anterior Papillary Muscle (APM)}

APM is the largest of the papillary muscles in the right ventricle. It arises from the right anterolateral ventricular wall. The length, origin, protrusion of muscle of bellies attached to anterior papillary muscles are tabulated in Table 1.

APM was present in all the cases.

In $63.3 \%$ cases, the muscle arose as a single head whereas in $36.7 \%$ cases there were two heads. In males, the incidence of single head was $70.6 \%$ and in females, it was $53.8 \%$. Conversely, double APM was more common in females (46.2\%) than in males (29.4\%) (Table 2).

Mean length of APM was $16.33 \mathrm{~mm}$ with a range of $2.5 \mathrm{~mm}$ $26.6 \mathrm{~mm}$. The mean length of APM was more in males than in females (Table 1). Single head of APM was always longer as compared to double heads (Table 3).

The origin of the APM was mainly from lower $1 / 3^{\text {rd }}$ of the ventricular wall (80.5\%). In rest of the cases $(19.5 \%)$, the muscle took origin from middle $1 / 3^{\text {rd }}$ of the right ventricular wall. APM did not arise from upper $1 / 3^{\text {rd }}$ of right ventricular wall.

Muscle belly of APM was intraluminal in all the cases. No mixed or sessile types were found. There was no predominant shape observed in APM. It was conical in $26.7 \%$, parallel in $20 \%$ and mamillated in $20 \%$ cases. In rest of the cases, it was flat, interlinked, $\mathrm{V}$ shaped, $\mathrm{H}$ shaped and two tiered (Table 4).

\begin{tabular}{|c|c|c|c|c|c|c|c|c|c|c|c|c|}
\hline \multirow{2}{*}{ 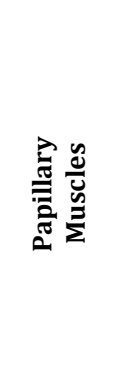 } & & \multirow{2}{*}{$\begin{array}{l}\vec{\Xi} \\
\vdots \\
\vdots \\
\vdots\end{array}$} & \multirow{2}{*}{ 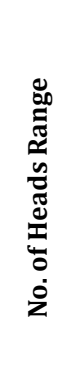 } & \multicolumn{2}{|c|}{ 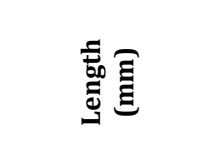 } & \multirow{2}{*}{$\begin{array}{l}\dot{H} \\
\dot{U} \\
0 \\
\dot{z} \\
\dot{z}\end{array}$} & \multicolumn{3}{|c|}{ 章 } & \multicolumn{3}{|c|}{ 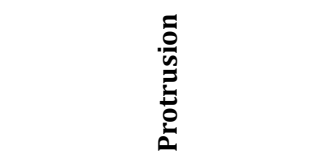 } \\
\hline & & & & 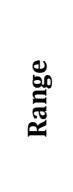 & 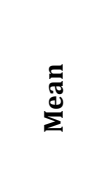 & & 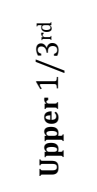 & 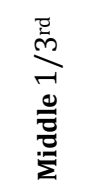 & 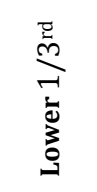 & 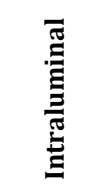 & 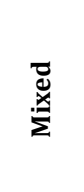 & 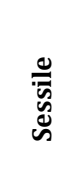 \\
\hline \multirow{4}{*}{$\begin{array}{c}\text { Anterior } \\
\text { (APM) }\end{array}$} & Total & $100.0 \%$ & $1-2$ & $\begin{array}{l}2.5- \\
26.6 \\
\end{array}$ & $\begin{array}{c}16.33 \pm \\
5.53 \\
\end{array}$ & $3-13$ & $0.0 \%$ & $19.5 \%$ & $80.5 \%$ & $100.0 \%$ & $0.0 \%$ & $0.0 \%$ \\
\hline & Male & $100.0 \%$ & $1-2$ & $\begin{array}{l}2.5- \\
26.6\end{array}$ & $\begin{array}{c}16.94 \pm \\
6.79 \\
\end{array}$ & 3-13 & $0.0 \%$ & $18.2 \%$ & $81.8 \%$ & $100.0 \%$ & $0.0 \%$ & $0.0 \%$ \\
\hline & Female & $100.0 \%$ & $1-2$ & $\begin{array}{l}9.9- \\
22.1 \\
\end{array}$ & $\begin{array}{c}15.63 \pm \\
3.61 \\
\end{array}$ & $4-10$ & $0.0 \%$ & $21.1 \%$ & $78.9 \%$ & $100.0 \%$ & $0.0 \%$ & $0.0 \%$ \\
\hline & P-value & - & 0.363 & - & 0.456 & - & - & 0.669 & 0.646 & - & - & - \\
\hline \multirow{2}{*}{$\begin{array}{c}\text { Posterior } \\
\text { (Ppm) }\end{array}$} & Total & $100.0 \%$ & $1-3$ & $\begin{array}{l}1.2- \\
24.2\end{array}$ & $\begin{array}{c}10.58 \pm \\
4.86\end{array}$ & $1-7$ & $17.2 \%$ & $59.4 \%$ & $23.4 \%$ & $100.0 \%$ & $0.0 \%$ & $0.0 \%$ \\
\hline & Male & $100.0 \%$ & $1-3$ & $\begin{array}{l}1.2- \\
22.3\end{array}$ & $\begin{array}{c}10.38 \pm \\
4.86\end{array}$ & $2-7$ & $16.7 \%$ & $58.3 \%$ & $25.0 \%$ & $100.0 \%$ & $0.0 \%$ & $0.0 \%$ \\
\hline
\end{tabular}




\begin{tabular}{|c|c|c|c|c|c|c|c|c|c|c|c|c|c|}
\hline & male & $100.0 \%$ & $1-3$ & $\begin{array}{l}3.2- \\
24.2\end{array}$ & $\begin{array}{c}10.84 \pm \\
4.49\end{array}$ & $1-7$ & $17.9 \%$ & $60.7 \%$ & $21.4 \%$ & $100.0 \%$ & $0.0 \%$ & $0.0 \%$ \\
\hline & & value & - & 0.896 & - & 0.715 & - & 0.913 & 0.845 & 0.806 & - & - & - \\
\hline \multirow{8}{*}{$\begin{array}{c}\text { Papillary } \\
\text { muscles } \\
\text { of Septal } \\
\text { Group }\end{array}$} & \multirow{4}{*}{$\begin{array}{l}\text { Septal } \\
\text { Papillary } \\
\text { Muscles } \\
(\mathrm{SPM})\end{array}$} & Total & $83.3 \%$ & $0-4$ & $\begin{array}{l}1.4- \\
9.0 \\
\end{array}$ & $\begin{array}{c}4.24 \pm \\
1.88 \\
\end{array}$ & $1-7$ & $39.5 \%$ & $53.5 \%$ & $7.0 \%$ & $84.0 \%$ & $4.0 \%$ & $12.0 \%$ \\
\hline & & Male & $82.4 \%$ & $0-4$ & $\begin{array}{l}1.7- \\
9.0\end{array}$ & $\begin{array}{l}4.23 \pm \\
1.97 \\
\end{array}$ & $1-5$ & $37.0 \%$ & $51.9 \%$ & $11.1 \%$ & $92.9 \%$ & $0.0 \%$ & $7.1 \%$ \\
\hline & & Female & $84.6 \%$ & $0-2$ & $\begin{array}{l}1.4- \\
7.7\end{array}$ & $\begin{array}{c}4.26 \pm \\
1.78\end{array}$ & $1-7$ & $43.8 \%$ & $56.2 \%$ & $0.0 \%$ & $72.7 \%$ & $9.1 \%$ & $18.2 \%$ \\
\hline & & $\begin{array}{c}\mathrm{P}- \\
\text { value }\end{array}$ & 0.875 & 0.326 & - & 0.957 & - & 0.861 & 0.589 & 0.234 & 0.187 & 0.268 & 0.420 \\
\hline & \multirow{4}{*}{$\begin{array}{c}\text { Medial } \\
\text { Papillary } \\
\text { Complex } \\
\text { (MPC) }\end{array}$} & Total & $80.0 \%$ & $0-4$ & $\begin{array}{l}1.2- \\
13.0\end{array}$ & $\begin{array}{c}4.83 \pm \\
2.56\end{array}$ & $0-6$ & $96.9 \%$ & $3.1 \%$ & $0.0 \%$ & $83.3 \%$ & $4.2 \%$ & $12.5 \%$ \\
\hline & & Male & $76.5 \%$ & $0-4$ & $\begin{array}{l}1.2- \\
9.2\end{array}$ & $\begin{array}{c}4.74 \pm \\
2.30\end{array}$ & $0-6$ & $100.0 \%$ & $0.0 \%$ & $0.0 \%$ & $92.3 \%$ & $0.0 \%$ & $7.7 \%$ \\
\hline & & Female & $84.6 \%$ & $0-2$ & $\begin{array}{l}2.4- \\
13.0 \\
\end{array}$ & $\begin{array}{c}4.96 \pm \\
2.95 \\
\end{array}$ & $1-4$ & $92.9 \%$ & $7.1 \%$ & $0.0 \%$ & $72.7 \%$ & $9.1 \%$ & $18.2 \%$ \\
\hline & & $\begin{array}{c}\mathrm{P}- \\
\text { value }\end{array}$ & 0.596 & 0.954 & - & 0.815 & - & 0.522 & 0.287 & - & 0.217 & 0.287 & 0.461 \\
\hline
\end{tabular}

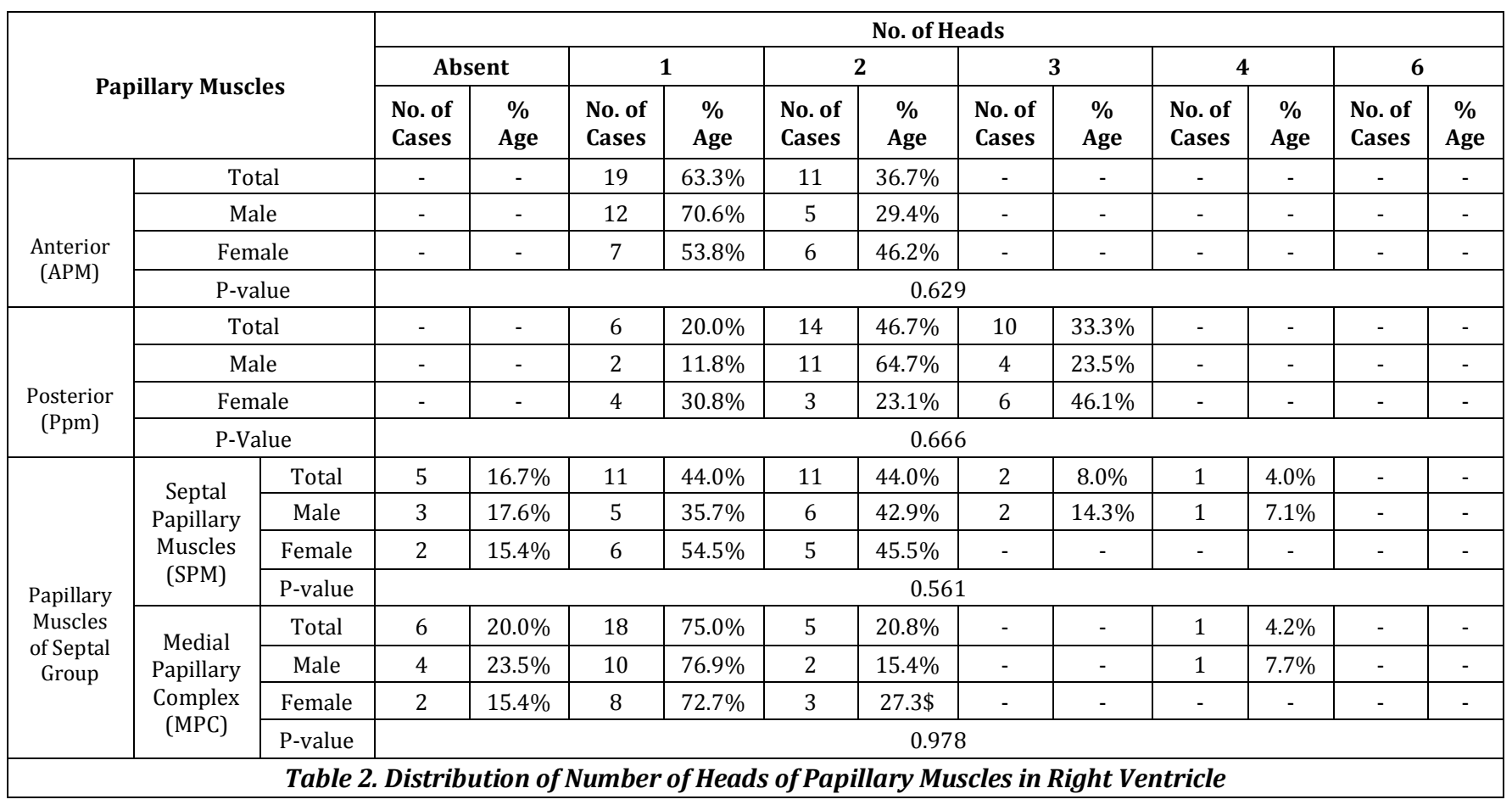

\begin{tabular}{|c|c|c|c|c|c|}
\hline & \multirow{2}{*}{ Papillary Muscles } & \multirow{2}{*}{ No. of Heads } & \multicolumn{3}{|c|}{ Length (mm) } \\
\hline & & & Min & Max & Mean \\
\hline & \multirow{2}{*}{ Anterior (APM) } & 1 & 7.3 & 26.4 & 18.09 \\
\hline & & 2 & 2.5 & 26.6 & 14.81 \\
\hline & \multirow{3}{*}{ Posterior (Ppm) } & 1 & 9.7 & 24.2 & 13.27 \\
\hline & & 2 & 3.9 & 22.3 & 12.4 \\
\hline & & 3 & 1.2 & 16.2 & 8.3 \\
\hline \multirow{8}{*}{ Septal } & \multirow{4}{*}{ Septal Papillary Muscles (SPM) } & 1 & 1.4 & 9 & 4.2 \\
\hline & & 2 & 1.8 & 8.9 & 4.5 \\
\hline & & 3 & 1.7 & 6 & 3.8 \\
\hline & & 4 & 2.6 & 4 & 3.5 \\
\hline & \multirow{4}{*}{ Medial Papillary Complex (MPC) } & 1 & 1.2 & 13 & 5 \\
\hline & & 2 & 2.5 & 8.3 & 4.6 \\
\hline & & 3 & - & - & - \\
\hline & & 4 & 2.8 & 9.2 & 4.6 \\
\hline
\end{tabular}




\begin{tabular}{|c|c|c|c|c|c|c|c|c|c|}
\hline \multirow{3}{*}{$\begin{array}{l}\text { No. of } \\
\text { Heads }\end{array}$} & \multirow{3}{*}{ Pattern } & \multirow{2}{*}{\multicolumn{2}{|c|}{ Anterior }} & \multirow{2}{*}{\multicolumn{2}{|c|}{ Posterior }} & \multicolumn{4}{|c|}{ Papillary Muscles of Septal Group } \\
\hline & & & & & & \multicolumn{2}{|c|}{ SPM } & \multicolumn{2}{|c|}{ MPC } \\
\hline & & $\begin{array}{l}\text { No. of } \\
\text { Cases }\end{array}$ & $\begin{array}{c}\% \\
\text { Age }\end{array}$ & $\begin{array}{l}\text { No. of } \\
\text { Cases }\end{array}$ & $\begin{array}{c}\% \\
\text { Age }\end{array}$ & $\begin{array}{l}\text { No. of } \\
\text { Cases }\end{array}$ & $\begin{array}{c}\% \\
\text { Age }\end{array}$ & $\begin{array}{l}\text { No. of } \\
\text { Cases }\end{array}$ & $\begin{array}{c}\% \\
\text { Age }\end{array}$ \\
\hline \multirow{4}{*}{1} & Conical & 8 & $26.7 \%$ & 3 & $10.0 \%$ & 9 & $36.0 \%$ & 11 & $45.8 \%$ \\
\hline & Mamillated & 6 & $20.0 \%$ & - & - & 1 & $4.0 \%$ & - & - \\
\hline & Arched & - & - & 1 & $3.3 \%$ & 1 & $4.0 \%$ & - & - \\
\hline & Sloped & - & - & 1 & $3.3 \%$ & - & - & 2 & $8.3 \%$ \\
\hline \multirow{5}{*}{2} & 2 Tiered & 1 & $3.3 \%$ & - & - & - & - & - & - \\
\hline & Interlinked & 2 & $6.7 \%$ & 2 & $6.9 \%$ & - & - & - & - \\
\hline & Parallel & 6 & $20.0 \%$ & 10 & $33.4 \%$ & 11 & $44.0 \%$ & 4 & $16.7 \%$ \\
\hline & $\mathrm{V}$ & 1 & $3.3 \%$ & 1 & $3.3 \%$ & - & - & 1 & $4.2 \%$ \\
\hline & $\mathrm{H}$ & 1 & $3.3 \%$ & 1 & $3.3 \%$ & - & - & - & - \\
\hline \multirow{6}{*}{3} & Parallel & - & - & 3 & $10.0 \%$ & 2 & $8.0 \%$ & - & - \\
\hline & Interlinked & - & - & 1 & $3.3 \%$ & - & - & - & - \\
\hline & $\begin{array}{c}2 \text { Interlinked + } 1 \\
\text { Separate }\end{array}$ & - & - & 1 & $3.3 \%$ & - & - & - & - \\
\hline & 2 Tiered + 1 Separate & - & - & 1 & $3.3 \%$ & - & - & - & - \\
\hline & V+1 Separate & - & - & 3 & $10.0 \%$ & - & - & - & - \\
\hline & $\mathrm{H}+1$ Separate & - & - & 1 & $3.3 \%$ & - & - & - & - \\
\hline 4 & Parallel & - & - & - & - & 1 & $4.0 \%$ & 1 & $4.2 \%$ \\
\hline
\end{tabular}

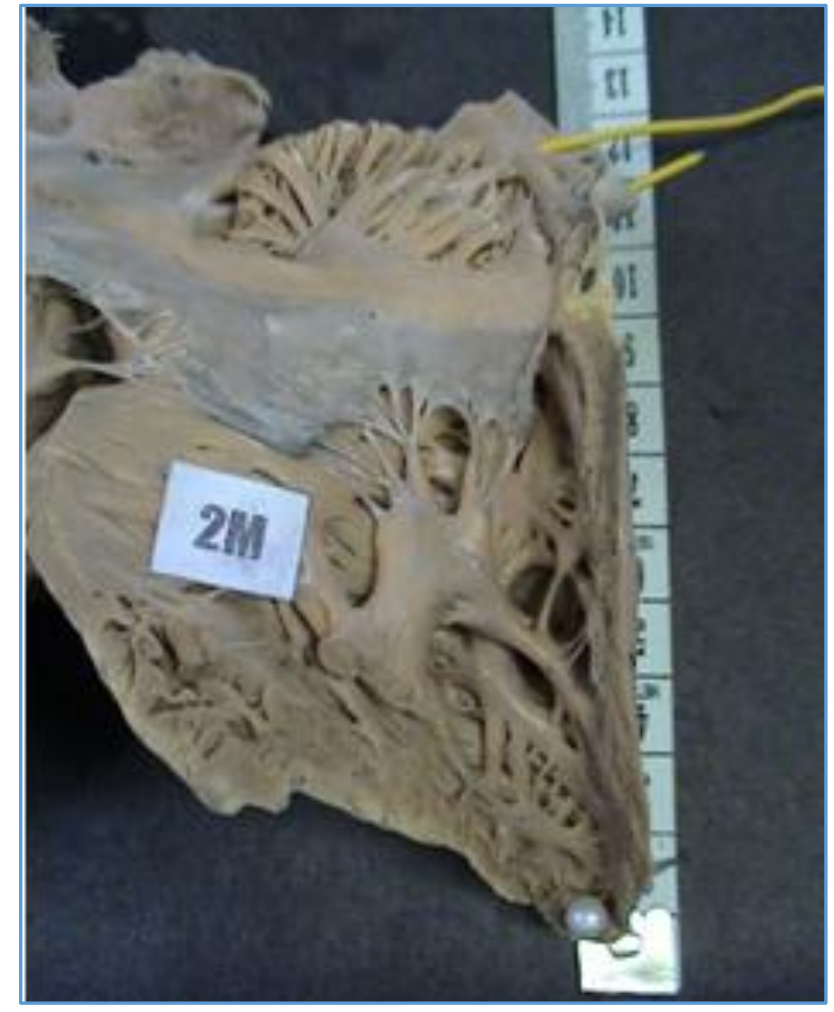

Figure 1. Mamillated Anterior Papillary Muscle

\section{Posterior Papillary Muscle (Ppm)}

Ppm arises from ventriculoseptal myocardium below posteroseptal commissure. It is frequently bifid or trifid.

The various parameters of posterior papillary muscle are tabulated in Table 1.

Ppm was present in all the cases. Number of heads ranged from 1 to 3 . Incidence of double heads was more than single or triple heads. In males, single head was present in $11.8 \%$, double heads in $64.7 \%$ and triple heads in $23.5 \%$ cases. In females, the incidence was $30.8 \%, 23.1 \%$ and $46.1 \%$ respectively (Table 2).

Mean length of Ppm was $10.58 \mathrm{~mm}$ and ranged from 1.2 to $24.2 \mathrm{~mm}$. Mean length of Ppm was more in females (10.84 mm) than in males (10.38 mm) (Table 1). Mean length of Ppm with single head was more as compared to that with double heads, which in turn was more than that of the triple heads (Table 3). Ppm took origin mainly from middle $1 / 3^{\text {rd }}$ of right ventricle (59.4\%). Number of cases of Ppm taking origin from middle $1 / 3^{\text {rd }}$ of right ventricle was more in females $(60.7 \%)$ than in males (58.3\%). In rest of the cases, the muscle took origin from lower $1 / 3^{\text {rd }}$ or upper $1 / 3^{\text {rd }}$ of right ventricle. Muscle belly of Ppm was intraluminal in all cases. No mixed or sessile types were found.

Muscle bellies were predominantly parallel in arrangement (43.4\% cases). The rest were conical, flat topped, arched (Fig. 3), sloped, interlinked, $\mathrm{V}$ shaped, $\mathrm{H}$ shaped, two interlinked +1 separate, two tiered +1 separate, $V+1$ separate, $H+1$ separate (Table 4 ).

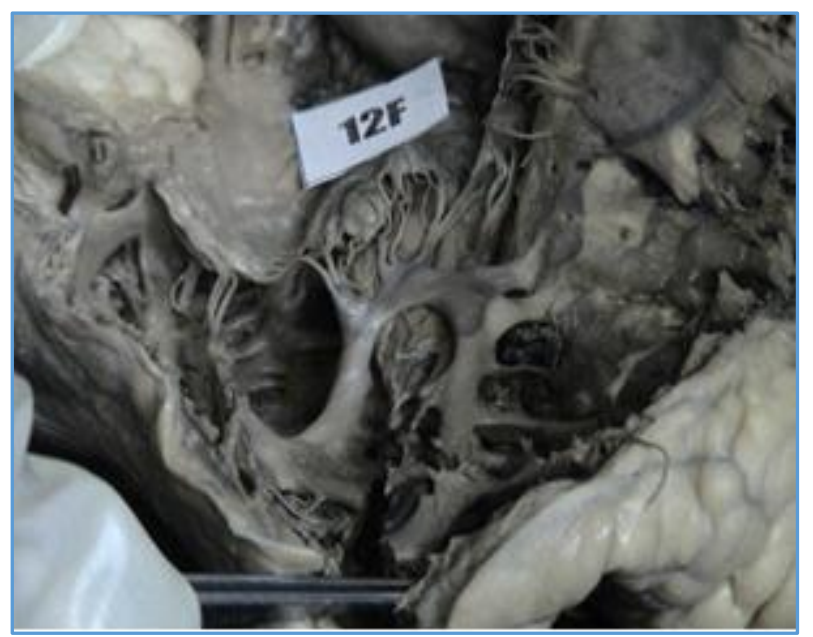

Figure 2. Arched Posterior Papillary Muscle of Right Ventricle 


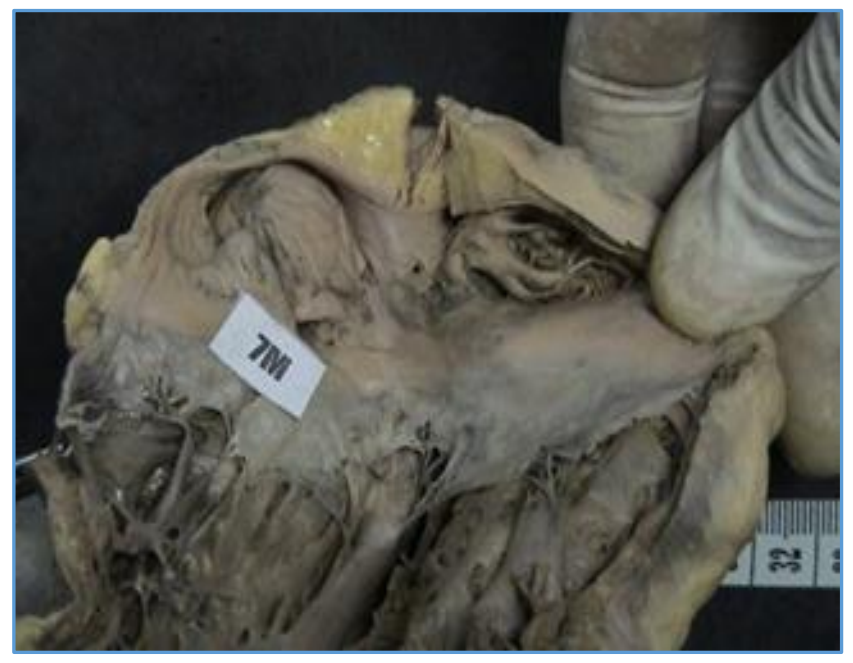

Figure 3. V-shaped Posterior Papillary Muscle of Right Ventricle

Papillary Muscles of Septal Group

It comprises of two groups, septal papillary muscles (SPM) and medial papillary complex (MPC). SPM mostly support the mid portion of septal leaflet of tricuspid valve while MPC supports the anterosuperior portion of the septal leaflet of tricuspid valve. The most anterior and prominent muscle of MPC is known as Lancisi's muscle.

The various parameters of papillary muscles of septal group are listed in Table 1.

\section{Septal Papillary Muscles (SPM)}

SPM was present in $83.3 \%$ cases.

Number of heads ranged from 1 to 4 . Single head of SPM was more common in females (54.5\%) than in males (35.7\%). Double heads of SPM were present in $42.9 \%$ cases in males and $45.5 \%$ cases in females. 3 and 4 heads of SPM were seen only in males (Table 2).

Mean length of SPM was $4.24 \mathrm{~mm}$ with a range of 1.4 to 9 $\mathrm{mm}$. Mean length of SPM was more in females $(4.26 \mathrm{~mm})$ than in males $(4.23 \mathrm{~mm})$ (Table 1$)$. Mean length of SPM was found to decrease as the number of heads increased except in the case of single and double heads. Mean length of double heads was more than that of single head (Table 3).

Origin of septal papillary muscle was from upper $1 / 3^{\text {rd }}$ of right ventricle in $37.0 \%$ cases, middle $1 / 3^{\text {rd }}$ in $51.9 \%$ and lower $1 / 3^{\text {rd }}$ in $11.1 \%$ cases in males. The values for females were $43.8 \%$ from upper $1 / 3^{\text {rd }}$ and $56.3 \%$ from middle $1 / 3^{\text {rd }}$ of right ventricle. In females, SPM did not arise from lower $1 / 3^{\text {rd }}$ of right ventricle.

Muscle bellies of septal papillary muscle were intraluminal in $92.9 \%$ and sessile in $7.1 \%$ cases in males. In females, the muscle bellies were intraluminal in $72.7 \%$, sessile in $9.1 \%$ and mixed in $18.2 \%$ cases.

The arrangement of muscle bellies was predominantly parallel (52\%) and conical (36\%). In rest of the cases, they were mamillated and arched in a small number of cases (Table 4).

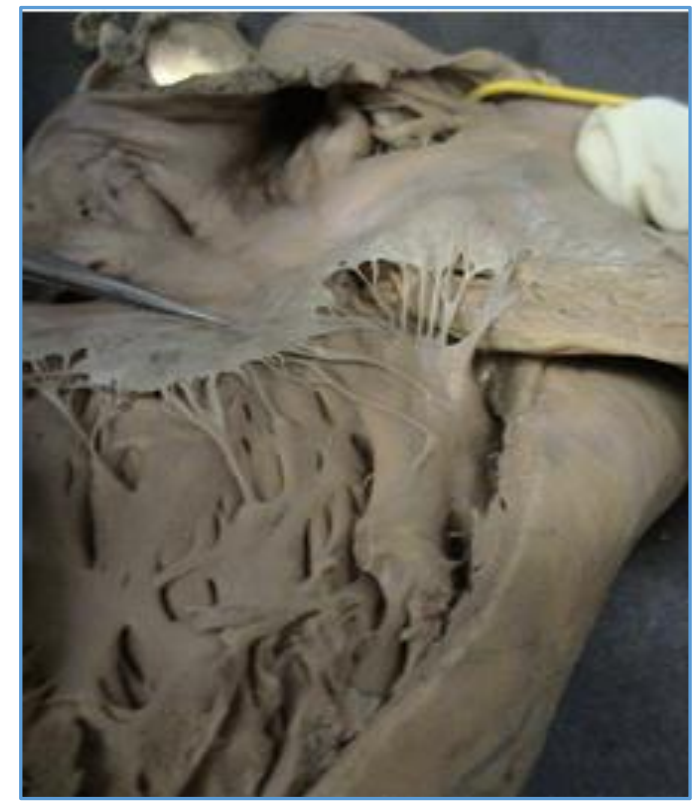

Figure 4. Septal Papillary Muscles (SPM) supporting Midportion and Medial Papillary Complex (MPC) supporting the Anterosuperior Portion of Septal Leaflet of Tricuspid Valve

Medial Papillary Complex (MPC)

MPC was present in $80 \%$ cases.

Number of heads of MPC ranged from 1 to 4 . Incidence of single head was $75 \%$, double heads $20.8 \%$ and 4 heads in $4.2 \%$ cases. 4 heads were present in only one male heart. Two heads were found more frequently in females than in males (Table 2).

Mean length of MPC was $4.83 \mathrm{~mm}$ with a range of 1.2 to 13 $\mathrm{mm}$. Mean length in males was less as compared with that in females (Table 1). Mean length of single head of MPC was more than that of double or 4 heads (Table 3).

Origin of medial papillary complex was from upper $1 / 3^{\text {rd }}$ of right ventricle in all the cases in males. In females, the origin of medial papillary complex was mainly from upper $1 / 3^{\text {rd }}$ of right ventricle $(92.9 \%)$ and in rest of the cases from middle $1 / 3^{\text {rd }}(7.1 \%)$.

Muscle bellies of medial papillary complex were intraluminal in $92.3 \%$ and sessile in $7.7 \%$ cases in males. In females, the muscle bellies were intraluminal in $72.7 \%$, sessile in $9.1 \%$ and mixed in $18.2 \%$ cases. The shape of muscle bellies was predominantly conical (45.8\%), flat topped $(20.8 \%)$ and parallel $(16.7 \%)$. The rest were sloped or V shaped. All the muscle bellies in the case with 4 heads were parallel (Table 4).

\section{CONCLUSIONS}

The present study was conducted on 30 human cadaveric hearts of north-west Indians to note the morphology and morphometry of papillary muscles of right ventricle. There were 17 male and 13 female hearts ranging in age from 17 to 75 years in age. The incidence, number of heads, length, shape, origin, protrusion of muscle bellies of papillary muscles of right ventricle were noted in detail in both males and females in an attempt to find gender differences in papillary muscles. The origin of all the three papillary muscles of the right ventricle from the ventricular wall was observed in the present study. The protrusion of muscle bellies in the ventricular cavity was also observed. 
In the present study, the origin of anterior papillary muscle was mainly from lower $1 / 3^{\text {rd }}$ of the wall; the origin of posterior and septal papillary muscles was mainly from the middle $1 / 3^{\text {rd }}$ of the ventricular wall. Anterior and posterior papillary muscle bellies were intraluminal in all the cases. Septal papillary muscle was also mainly intraluminal although a small number of mixed and sessile types were also found.

A study by Restivo et $\mathrm{al}^{4}$ has reported the topography of medial papillary complex from septal papillary muscles.

\section{Anterior Papillary Muscle (APM)}

APM was present in all the cases in the present study as has also been reported in literature. $2,8,9,10$

The percentage of incidence of heads of APM is variable. APM has been described, as being occasionally bifid. ${ }^{2}$ Single head was found in $70.6 \%$ cases in males and $53.8 \%$ cases in females in the present study. The difference was not statistically significant. Nigri et $\mathrm{al}^{8}$ described presence of single head in $79 \%$ cases (77\% in males and $95 \%$ in females).

Shape of APM was conical (61\%), flat topped (24.4\%) or mamillated (14.6\%). These values are almost similar to those found by Nigri et al ${ }^{8}$. However, these authors ${ }^{8}$ also found arched and wavy type of APM in $4.3 \%$ and $1 \%$ of cases respectively. The present study did not come across these shapes.

In the present study, mean length of single head of APM was $18.09 \mathrm{~mm}$ and of double heads was $14.81 \mathrm{~mm}$. The corresponding figures in the Caucasian study are $20.2 \mathrm{~mm}$ and $13.70 \mathrm{~mm}$ respectively. Both the studies have found that the single head of APM is always longer as compared to double head.

\section{Posterior Papillary Muscle (Ppm)}

Ppm was present in all the cases in the present study as well as the other reports. $2,8,9,10$

Number of heads ranged from 1 to 3 in the present study which is in conformation with the standard text books of anatomy.2,9,10 Four heads of Ppm were seen only in the study by Nigri et al. 8 The incidence of two heads of Ppm is the most common arrangement found in the present study as well as others. ${ }^{8}$ The incidence of 3 heads was $33 \%$ in the present study, which is higher as compared to the Caucasian study ${ }^{8}$ $(20 \%)$. There are some variations in the incidence of heads in males and females but no statistically significant difference was found.

The shape of Ppm was conical in $75 \%$ hearts. A few cases of flat topped (9.4\%), mamillated (7.8\%), arched $(6.2 \%)$ and sloped (1.6\%) muscles were also observed. When compared to the Caucasian study ${ }^{8}$ the observations were almost similar. The other defined shapes such as grooved and stepped types were not found in the present study.

Mean length of Ppm with single head was less in the present study than that found in Americans. ${ }^{8}$ Mean length of Ppm with single head was more as compared to that with double heads which in turn was more than that of the triple heads. Similar findings were reported by Nigri et al. ${ }^{8}$

\section{Papillary Muscles of Septal Group}

Papillary muscles of septal group have been described under one heading8 or separately as septal papillary muscle (SPM) and medial papillary muscles (MPC). ${ }^{4,11}$ Wafae et al ${ }^{12}$ has described these as septal inferior papillary muscle and septal infundibular papillary muscle. The muscles in the present study have been described as SPM and MPC respectively.

\section{Septal Papillary Muscles (SPM)}

The complete absence of SPM was discussed by various authors. $2,8,10$ According to standard textbooks of anatomy, SPM may be absent or exist merely as irregular fibrous cords ${ }^{2}$. Nigri et $\mathrm{al}^{8}$ reported absence of SPM in $21 \%$ cases. In the present study MPC was absent in 20\% cases and SPM was absent in $16.7 \%$ cases. Both the groups were absent in $10 \%$ of cases.

Number of heads ranged from 1 to 4 . Single, triple and quadruple heads were more common in Caucasians ${ }^{8}$ than in north-west Indians while double heads were found more frequently in the present study.

Conical muscle bellies of SPM showed a higher incidence in the present study as compared to the study of Nigri et al ${ }^{8}$ while a lower incidence of flat topped bellies was observed. Mamillated and arched types of bellies were found in almost equal numbers in the present study and study by Nigri et al. ${ }^{8}$

Mean length of single head of SPM was less in the present study than the mean length found by Nigri et al ${ }^{8}$ Mean length of double heads of SPM was slightly more in the present study than that of Nigri et $\mathrm{al}^{8}$ Mean length of SPM was found to decrease as the number of heads increased except in the case of single and double heads. Mean length of double heads was more than that of single head in the present study. But in the case of study by Nigri et $\mathrm{al}^{8}$ mean length decreased as number of heads of SPM increased in all the cases.

\section{Medial Papillary Complex (MPC)}

A few studies have been done on medial papillary complex, ${ }^{4,11}$ but they have focused only on the location and the development of the medial papillary complex. According to Wenink, 11 morphology of MPC changes with increasing age with changes in haemodynamics of the heart.

Some authors ${ }^{4,13}$ describe the Lancisi's muscle as the most prominent muscle in MPC. According to them, this muscle has been described in literature but the knowledge of its anatomy is very limited. MPC is located in immediate sub-infundibular position. These studies are mainly focused on the variations found in location of MPC.

In the present study, origin of medial papillary complex was mainly from upper $1 / 3^{\text {rd }}$ of right ventricle and only in a small number from middle $1 / 3^{\text {rd }}$ of right ventricle. It did not arise from the lower $1 / 3^{\text {rd }}$ of right ventricle.

The present study was done with a purpose to find out the gross morphology and size of papillary muscles in right ventricles and compare our findings with other studies and note any gender differences among them. The morphometry of papillary muscles is very useful during mitral and tricuspid valve repair.

Anterior and posterior papillary muscles of right ventricle were always present while both groups of papillary muscles of septal group were absent in $10 \%$ cases.

Number of heads of papillary muscles ranged from 1 to 4 in right ventricle. Single head was more common in case of anterior papillary muscle (APM) of right ventricle. In case of Ppm, double heads were more common.

In the right ventricle, anterior papillary muscle was longer in males than in females while rest of the papillary muscles of right ventricle were longer in females. The differences were not statistically significant. 
Mean length of papillary muscles was found to decrease in the present study as the number of heads increased except in the case of SPM. Mean length of double heads of SPM was more than that of single head in the present study.

There is a trend of upward shift of origin of papillary muscles in the right ventricle from anterior papillary muscle, posterior papillary muscle, septal papillary muscle to medial papillary complex.

The mean length of single head of papillary muscles of right ventricle was less in north-west Indian hearts as compared to Caucasian hearts ${ }^{8}$.The length of double or more heads was more in the present study than in Caucasian study ${ }^{8}$ except in case of 3 or 4 heads of SPM.

\section{REFERENCES}

1. Burch GE, DePasquale NP, Phillips JH. The syndrome of papillary muscle dysfunction. Am Heart J 1968;75(3):399415.

2. Williams PL, Warwick R, Dyson M, et al. Gray's anatomy. 37th edn. London: Churchill Livingstone 1989:703-11.

3. Silver MD, Lam JHC, Ranganathan N, et al. Morphology of the human tricuspid valve. Circulation 1971;43(3):333-48.

4. Restivo A, Smith A, Wilkinson JL, et al. The medial papillary muscle complex and its related septomarginal trabeculation. A normal anatomical study on human hearts. J Anat 1989;163:231-42.

5. Mittal AK, Langston M, Cohn KE, et al. Combined papillary muscle and left ventricular wall dysfunction as a cause of mitral regurgitation. An experimental study. Circulation 1971;44(2):174-80.

6. Roberts WC, Braunwald E, Morrow AG. Acute severe mitral regurgitation secondary to ruptured chordae tendineae: clinical, hemodynamic, and pathologic considerations. Circulation 1966;33(1):58-70.

7. Ronan JA, Steelman RB, deLeon AC, et al. The clinical diagnosis of acute severe mitral insufficiency. Am J Cardiol 1971;27(3):284-90.

8. Nigri GR, Di Dio LJ, Baptista CA. Papillary muscles and tendinous cords of the right ventricle of the human heart: morphological characteristics. Surg Radiol Anat 2001;23(1):45-9.

9. Walls EW. The blood vascular and lymphatic systems. $12^{\text {th }}$ edn. In: Romanes GJ. Cunningham's textbook of anatomy. Oxford: Oxford University Press 1981:880-5.

10. Rosse C, Gaddum-Rosse P. Hollinshead's Textbook of Anatomy. $5^{\text {th }}$ edn. Philadelphia: Lippincott-Raven Publishers 1997:473-6.

11. Wenink AC. The medial papillary complex. Br Heart J 1977;39(9):1012-8.

12. Wafae N, Hayashi H, Gerola LR, et al. Anatomical study of the human tricuspid valve. Surg Radiol Anat 1990;12(1):37-41.

13. Tandler J. Anatomie des herzens. 1st edn. In: von Bardeleben K, (edr). Handbuch der anatomie des menschen. Vol 3. Jena: Gustav Fischer 1913:p 88. 